\title{
Symptoms following mild head injury: expectation as aetiology
}

\author{
Wiley Mittenberg, Diane V DiGiulio, Sean Perrin, Anthony E Bass
}

\begin{abstract}
An affective, somatic, and memory checklist of symptoms was administered to subjects who had no personal experience or knowledge of head injury. Subjects indicated their current experiences of symptoms, then imagined having sustained a mild head injury in a motor vehicle accident, and endorsed symptoms they expected to experience six months after the injury. The checklist of symptoms was also administered to a group of patients with head injuries for comparison. Imaginary concussion reliably showed expectations in controls of a coherent cluster of symptoms virtually identical to the postconcussion syndrome reported by patients with head trauma. Patients consistently underestimated the premorbid prevalence of these symptoms compared with the base rate in controls. Symptom expectations appear to share as much variance with postconcussion syndrome as head injury itself. An aetiological role is suggested.
\end{abstract}

Postconcussion syndrome (PCS) is a cluster of symptoms that includes complaints of memory difficulty, headache, vertigo, depression, anxiety, concentration difficulty, blurred vision, fatigue, irritability, photophobia, and hyperacoutism. ${ }^{1}$ PCS is a persistent phenomenon $^{2-4}$ that is resistant to current treatments. ${ }^{5}$ The causes of PCS are controversial. Binder ${ }^{6}$ reviewed neuropsychological, neurophysiological, and neuropathological evidence that the primary cause of PCS is cerebral dysfunction. Elsewhere, it has been argued that although PCS may initially have an organic basis, it persists because of psychological factors or is primarily psychogenic in origin. ${ }^{7-10}$ The incidence of the syndrome appears to be inversely related or unrelated to severity of head injury or neuropsychological status. ${ }^{11-13}$

The presentation of the PCS cluster of symptoms across samples of patients with head injuries is remarkably consistent, although the reported incidence varies widely across studies. ${ }^{810^{12-15}}$ The high frequency and universality of PCS subsequent to head trauma has suggested that the underlying common denominator, cerebral insult, is the principal cause. ${ }^{5}$ However, these same symptoms may occur with equal frequency in uninjured individuals. $^{121316}$

Benign emotional and physiological symptoms may be misinterpreted by patients as the results of brain injury. Individuals ascribe cognitive meaning to symptoms by examining the context in which they occur and in terms of the ideas they have about the symptoms. ${ }^{17-19}$ This study was designed to determine whether symptoms of mild cerebral trauma could be related to what patients believe to be the likely symptoms that occur after head injury.

\section{Method}

SUBJECTS

The control group consisted of 223 volunteers [mean (SD) age, 30.2 (9.9) years; mean (SD) education, $14.6(2 \cdot 3)$ years], who were recruited by canvassing local businesses, apartment complexes, shopping centres, evening or weekend adult education classes, and a local community college. Twenty eight per cent were employed in professional and technical occupations, 34\% held management, administration, clerical, or sales positions, $8 \%$ were craftsmen or foremen, $10 \%$ were employed as service workers, farmers, or operatives, $4 \%$ were labourers or farm foremen, and $16 \%$ were homemakers, students, or retirees. Predicted mean (SD) IQ for the group was $107 \cdot 2(6 \cdot 8)$ as estimated from demographic variables. ${ }^{20}$ Subjects who reported a history of head injury or who knew a head injured individual well were excluded from the control group.

The comparison group was made up of a sample of 100 patients with head injuries [mean (SD) age $=33.4,(13 \cdot 1)$; mean (SD) education $=13 \cdot 5,(3 \cdot 1)]$. The subjects were consecutive outpatient referrals for neuropsychological examination subsequent to head trauma. They were seen either at the outpatient clinic of a hospital neurology department, a university neuropsychology clinic, or the private offices of a neurologist. The group thus constitutes a sample of patients with postconcussion complaints or suspected complications rather than a random sample of individuals with head injuries. Fifteen per cent were employed in professional and technical occupations, $26 \%$ held management, administration, clerical, or sales positions, $20 \%$ were craftsmen or foremen, $17 \%$ were employed as service workers, farmers, or operatives, $1 \%$ were labourers or farm foremen, and $21 \%$ were homemakers, students, or retirees. Predicted IQ for the group was $103 \cdot 2(7 \cdot 4)$ as estimated from demographic variables. ${ }^{20}$

Sixty four of the patients had sustained closed head injuries in motor vehicle accidents, eight were struck by blunt objects, and 28 had sustained head trauma in falls. Patients were 
seen an average of 1.7 years after injury. Injuries had occurred less than six months before the evaluation in 39 patients, 19 were six to 12 months after trauma, and 42 patients had suffered head injuries more than one year before evaluation. Average reported length of unconsciousness was 23 minutes. Twenty seven subjects had not lost consciousness, 33 were unconscious for less than five minutes, 18 lost consciousness for between five and 10 minutes, 14 for more than 10 minutes but no more than half an hour, and eight patients were unconscious for more than 30 minutes. Although the Glasgow Coma Scale scores were not available, $92 \%$ of the sample were reported as being alert and responsive within 30 minutes of the head injury.

\section{PROCEDURE}

A 30 symptom checklist that included affective, somatic, and memory items was administered to each subject. The control group was asked to indicate which symptoms they currently experienced, to then imagine that they were involved in a motor vehicle accident as described in a vignette, and to endorse symptoms they expected to experience after sustaining a head injury. The specific instructions read as follows:

"Automobile accidents are a fact of life and can happen to anyone. We are interested in your opinion of how such an accident might affect your ability to do everyday things. We would like you to imagine for a moment that you were driving to the store at night about six months ago when another car turned into you. You were knocked out for a while and when you woke up you were in the hospital. Imagine that you had to stay in the hospital for a week or two to recover. Try to imagine that you had this accident about six months ago, and answer the questions below as you would have before you had the accident (how you usually are) AND how you think you might answer the questions after an accident like this. If you aren't sure how to answer, guess. Yes means you would have the symptom usually or often, and no means you would rarely or never have the symptom."

The patients with head injuries completed the same checklist of symptoms according to the following instructions: "Head injuries are a fact of life and can happen to anyone. We are interested in how your head injury has (or has not) affected your ability to do everyday things. Answer the questions below as you would have before the accident (how you used to be) and then tell us if you notice the symptom now (after the accident). If you aren't sure how to answer, guess. Yes means you have the symptom usually or often, and no means you rarely or never have the symptom."

\section{Results}

COMPARISON BETWEEN EXPECTED AND ACTUAL POSTCONCUSSION SYMPTOMS

Cronbach's alpha $(0.93)$ indicated that the checklist of 30 symptoms was a reliable measure of postconcussion symptoms in the group with injuries. Coefficient alpha for the normal control group $(0.91)$ suggested that their expectations also formed an internally consistent "syndrome". The average patient with head trauma reported $13.8(8.3)$ of the 30 symptoms, compared to $14.8(7 \cdot 6)$ symptoms anticipated by the control group. The number of symptoms reported by patients did not differ significantly from the number expected by controls $(t(321)=1 \cdot 01, \mathrm{p}>0 \cdot 20)$.

The percentage of subjects in each group that endorsed specific symptoms appears in table 1 . These percentages do not include those who reported premorbid occurrence of a given symptom. Chi-square tests were performed to compare the frequency of these with head injuries and normal control subjects who endorsed each item.

Twenty two of the 30 symptoms were anticipated at frequencies that did not differ significantly $(p>0.05)$ from those reported following actual concussion. Headaches and visual difficulties were expected more often than they actually occurred. Irritability, fatigue and difficulty remembering names, telephone conversations, conversations during the day, or why .one entered a room were somewhat more likely to occur than expected. Nevertheless, inspection of table 1 suggests that a fair amount of correspondence exists between the expectation and experience of postconcussion syndrome.

To further examine this correspondence, symptoms were rank ordered from the most to least frequent in each group of subjects. The resulting rank order correlation $\left(\mathrm{r}_{\mathrm{s}}(28)=0.82\right.$, $\mathrm{p}<0.001)$ indicated that the relative incidence of postconcussion symptoms reported by patients with head trauma and the relative frequency of postconcussion symptoms anticipated by uninjured controls shared about $67 \%$ of their variance.

COMPARISON BETWEEN NORMAL BASE RATES AND PATIENTS' PREMORBID SYMPTOM ESTIMATES

If patients reattribute benign emotional and physiological symptoms to their head injury, they would be expected to underestimate the occurrence of these symptoms before trauma. To examine this possibility, the base rate of postconcussion symptoms in normal controls was compared with retrospective patient accounts of their condition before trauma. Patients reported fewer premorbid symptoms overall, mean (SD) $2 \cdot 0,(3 \cdot 1)$ compared with normal controls, $4.9,(4 \cdot 8)$, and this difference was statistically significant $(t(321)=6.35$, $\mathrm{p}>0.001$ ).

Table 2 shows that patients with head injuries significantly underestimated the premorbid frequency of 21 out of 30 specific symptoms when compared to the base rates in normal controls. There was a non-significant trend in the same direction for seven of the nine remaining symptoms. Results suggest a tendency for patients with head injuries to attribute premorbid symptoms to head trauma. 
Table 1 Incidence of Expected and Actual Postconcussion Symptoms

\begin{tabular}{lll} 
& $\begin{array}{l}\text { Percentage Controls } \\
\text { Expecting } \\
(n=223)\end{array}$ & $\begin{array}{l}\text { Percentage Head } \\
\text { Injured Reporting } \\
(n=100)\end{array}$ \\
\hline Headache & $80 \cdot 0$ & $59 \cdot 1^{\star \star}$ \\
Anxiety & $68 \cdot 1$ & $58 \cdot 3$ \\
Depression & $67 \cdot 6$ & $63 \cdot 2$ \\
Concentration difficulty & $66 \cdot 8$ & $70 \cdot 5$ \\
Dizziness & $63 \cdot 3$ & $52 \cdot 0$ \\
Blurry or double vision & $58 \cdot 1$ & $45 \cdot 4^{\star}$ \\
Trouble thinking & $54 \cdot 1$ & $57 \cdot 6$ \\
Irritability & $50 \cdot 0$ & $65 \cdot 9^{\star}$ \\
Fatigue & $47 \cdot 2$ & $63 \cdot 9^{\star \star}$ \\
Sensitivity to bright light & $44 \cdot 8$ & $40 \cdot 2$ \\
Forgets where car was parked & $40 \cdot 4$ & $38 \cdot 7$ \\
Loses car keys & $38 \cdot 3$ & $35 \cdot 1$ \\
Forgets directions & $35 \cdot 5$ & $36 \cdot 8$ \\
Forgets why they entered a room & $34 \cdot 8$ & $50 \cdot 6^{\star}$ \\
Forgets content of daily conversations & $34 \cdot 4$ & $48 \cdot 4^{\star}$ \\
Forgets groceries & $33 \cdot 8$ & $41 \cdot 8$ \\
Gets lost when driving & $32 \cdot 0$ & $27 \cdot 1$ \\
Forgets store locations in shopping centre & $32 \cdot 0$ & $30 \cdot 8$ \\
Forgets yesterday's breakfast & $30 \cdot 7$ & $31 \cdot 9$ \\
Forgets appointment dates & $29 \cdot 8$ & $39 \cdot 8$ \\
Loses wallet or pocketbook & $28 \cdot 5$ & $27 \cdot 7$ \\
Loses items around the house & $28 \cdot 5$ & $28 \cdot 1$ \\
Forgets yesterday's newspaper stories & $28 \cdot 1$ & $36 \cdot 1$ \\
Forgets recent telephone conversations & $27 \cdot 9$ & $40 \cdot 6^{\star}$ \\
Forgets faces of new acquaintances & $24 \cdot 5$ & $23 \cdot 7$ \\
Forgets names of new acquaintances & $23 \cdot 5$ & $37 \cdot 5^{\star}$ \\
Forgets who telephoned recently & $21 \cdot 4$ & $30 \cdot 9$ \\
Forgets who they saw yesterday & $20 \cdot 9$ & $29 \cdot 9$ \\
Forgets television news stories & $20 \cdot 4$ & $28 \cdot 9$ \\
Forgets where they went today & $18 \cdot 9$ & $22 \cdot 5$ \\
\hline & & \\
\hline Note: chisquare * $0.05 \star *$ & &
\end{tabular}

Note: chi-square ${ }^{\star} p<0.05{ }^{\star \star} p<0.01$ two tailed.

Table 2 Normal Base Rates and Patients' Premorbid Estimates of Postconcussion Symptoms

\begin{tabular}{llc}
\hline & $\begin{array}{l}\text { Frequency in Controls } \\
(n=223)\end{array}$ & $\begin{array}{c}\text { Premorbid Frequency } \\
\text { Estimate by Patients } \\
(n=100)\end{array}$ \\
\hline Forgets where car was parked & $32 \cdot 0 \%$ & $7 \cdot 0^{\star \star}$ \\
Loses car keys & $31 \cdot 0$ & $6 \cdot 0^{\star \star}$ \\
Forgets groceries & $28 \cdot 3$ & $9 \cdot 0^{\star \star}$ \\
Forgets yesterday's breakfast & $26 \cdot 9$ & $9 \cdot 0^{\star \star}$ \\
Forgets why they entered a room & $26 \cdot 5$ & $11 \cdot 0^{\star \star}$ \\
Forgets directions & $24 \cdot 2$ & $13 \cdot 0^{\star}$ \\
Anxiety & $24 \cdot 2$ & $16 \cdot 0^{\star}$ \\
Forgets appointment dates & $20 \cdot 2$ & $7 \cdot 0^{\star \star}$ \\
Forgets store locations in shopping centre & $20 \cdot 0$ & $9 \cdot 0^{\star \star}$ \\
Depression & $19 \cdot 7$ & $13 \cdot 0$ \\
Loses items around the house & $17 \cdot 0$ & $4 \cdot 0^{\star \star}$ \\
Forgets yesterday's newspaper stories & $17 \cdot 0$ & $6 \cdot 0^{\star \star}$ \\
Loses pocketbook or wallet & $16 \cdot 6$ & $6 \cdot 0^{\star \star}$ \\
Forgets content of daily conversations & $16 \cdot 6$ & $9 \cdot 0^{\star}$ \\
Forgets faces of new acquaintances & $16 \cdot 0$ & $7 \cdot 0^{\star}$ \\
Irritability & $15 \cdot 7$ & $9 \cdot 0$ \\
Sensitivity to bright light & $13 \cdot 9$ & $8 \cdot 0$ \\
Concentration difficulty & $13 \cdot 5$ & $5 \cdot 0^{\star}$ \\
Fatigue & $12 \cdot 6$ & $3 \cdot 0^{\star \star}$ \\
Headache & $12 \cdot 5$ & $7 \cdot 0$ \\
Forgets who they saw yesterday & $12 \cdot 1$ & $3 \cdot 0^{\star \star}$ \\
Forgets television news stories & $12 \cdot 1$ & $3 \cdot 0^{\star \star}$ \\
Forgets names of new acquaintances & $10 \cdot 1$ & $12 \cdot 0$ \\
Gets lost when driving & $9 \cdot 0$ & $4 \cdot 0$ \\
Forgets recent telephone conversations & $8 \cdot 5$ & $4 \cdot 0$ \\
Blurry or double vision & $8 \cdot 1$ & $3 \cdot 0^{\star}$ \\
Dizziness & $7 \cdot 2$ & $2 \cdot 0^{\star}$ \\
Trouble thinking & $6 \cdot 3$ & $1 \cdot 0^{\star}$ \\
Forgets who telephoned recently & $5 \cdot 8$ & $6 \cdot 0$ \\
Forgets where they went today & $4 \cdot 9$ & $2 \cdot 0$ \\
\hline Note chisquare & & \\
\hline & &
\end{tabular}

Note: chi-square ${ }^{\star} p<0.05{ }^{\star \star} p<0.01$ one-tailed.

Table 3 Correlations between reported symptom frequencies and demographic characteristics

\begin{tabular}{llllll}
\hline & \multicolumn{2}{l}{ Premorbid symptoms } & & \multicolumn{2}{c}{ Postconcussion symptoms } \\
\cline { 2 - 3 } \cline { 5 - 6 } \cline { 5 - 6 } & Patients & Controls & & Patients & Controls \\
\hline Length of unconsciousness & -0.02 & - & & -0.15 & - \\
Time since injury & -0.11 & - & & 0.03 & - \\
Age & -0.05 & $-0.16^{\star}$ & & 0.08 & -0.08 \\
Education & -0.09 & $-0.22^{\star}$ & & -0.18 & -0.13 \\
Gender & -0.10 & 0.10 & & 0.02 & 0.09 \\
\hline
\end{tabular}

Note: Pearson $r^{\star} p<0.05$.
RELATIONSHIPS BETWEEN SYMPTOMS AND

DEMOGRAPHIC VARIABLES

Table 3 displays the correlations between reported symptom frequencies and demographic characteristics in the patient and control groups. There were no significant relationships between the number of postconcussion symptoms reported in the head trauma group and length of unconsciousness, the length of time that had elapsed since the injury, or the type of injury $(F(2,97)=0.05, p=0.95)$. These associations may have been limited by the restricted range of the severity of the head injuries in the sample. Post-trauma symptom frequencies were unrelated to the patient's age, gender, or occupational status category $(F(5,217)=1.95, p=0.09)$. There was a nonsignificant trend for subjects who were more educated to report fewer postconcussion symptoms in both the patient and control groups.

The number of premorbid symptoms reported by patients was unrelated to their age, gender, or level of education. Fewer premorbid symptoms, however, were reported by older and more educated control subjects.

The control group was an average of 3.2 years younger than the patient group $(t(321)=2 \cdot 18, \mathrm{p}<0.05$ and had 1.1 years more education $(t(321)=3.18, \mathrm{p}<0.01)$. These differences are not likely to have affected the results substantially given their size and the minimal relationship between symptom frequency and demographic variables.

\section{Discussion}

The high frequency with which PCS occurs and persists after mild head injury suggests that these symptoms are somehow related to neurological insult. ${ }^{5}$ Neurophysiological mechanisms have been proposed, but the supporting neurological and neuropsychological evidence is controversial. ${ }^{621}$ Arguably the consistency of the symptom cluster across patient series indicates that the one underlying common denominator, cerebral dysfunction, is the principal aetiology. ${ }^{5}$ This study suggests another common denominator: the anticipation, widely held by individuals who have had no opportunity to observe or experience postconcussive symptoms, that PCS will occur following mild head injury.

Current results indicate common expectations of post-concussive headache, anxiety, depression, concentration difficulty, vertigo, diplopia, confusion, irritability, fatigue, and photophobia and memory difficulties. These symptoms are anticipated at relatively high levels of probability and form an internally consistent "syndrome". Their rate of expected incidence differed little from the observed incidence of these same symptoms in patients with head injuries. Moreover, the relative incidence of postconcussion symptoms reported by head trauma patients correlated substantially $\left(r_{s}=0.82\right)$ with the relative frequency of postconcussion symptoms anticipated by uninjured controls. Patients with head injuries consistently underestimated the normal prevalence of these symptoms in 
their retrospective accounts compared with the base rate reported by normal controls. This result suggests that patients may reattribute benign emotional, physiological, and memory symptoms to their head injury.

That an imaginary concussion will reliably elicit expectations of a coherent cluster of symptoms virtually identical to PCS implies that expectations share almost as much variance with the syndrome as head injury itself. A causative role is suggested.

The above arguments do not suggest that PCS reflects underlying personality disorder. Common expectations and experiences define reality rather than abnormality. Current evidence suggests that for at least some patients the aetiological sequence of PCS may begin with : 1) Activation of typical symptom expectancies when mild head injury occurs. The concussion is inherently stressful and also normally induces autonomic/emotional arousal; 2) Symptom expectancies bias selective attention to internal state; 3) Attentional bias and arousal augment symptom perception; 4) which then elicits additional autonomic/emotional response, reinforcing expectations.

The aetiological role of expectations may also explain why persistent PCS is uncommon following mild head injuries sustained by children $^{22-23}$ and in athletic competition. ${ }^{2425}$ Children are less able to appreciate the health risks of head trauma, and are therefore less likely to appraise any minor injury as a potential source of persistent symptoms. Children are also less likely to have developed specific expectations of postconcussion headache, anxiety, depression, memory, or concentration impairment. Participants in boxing, football, and other contact sports are repeatedly observed to sustain minor head trauma without obvious persistent ill effects. Being "knocked out" or "dazed" in the context of an athletic event is therefore less likely to elicit anticipations of persistent postconsussion syndrome than identical experiences that occur in the context of a motor vehicle accident.

PCS symptoms occur frequently in the normal population, and at a rate that appears similar to their frequency of occurrence following head injury. ${ }^{1216}$ Expectations about the symptoms of concussion would result in reattribution of these symptoms to the trauma, selective attention to the symptoms, and anxiety about their significance. Both selective attention and anxiety increase the subjective intensity of symptoms, eliciting further anxiety. ${ }^{26}$ This circular reinforcement of expectations may explain why PCS persists following mild head injury in the absence of impairment on formal neuropsychological examination, ${ }^{11}{ }^{12}$ and why the syndrome appears to be inversely related or unrelated to the severity of head trauma. ${ }^{4101314}$

Symptom expectations, selective attention, and anxiety can, under certain circumstances, interact to produce syndromes that mimic essentially any pathological process. This situation characterises "medical students' disease", which has a prevalence of approximately $70 \%$ in medical schools. ${ }^{27}$ Physician consultations are sought for cardiac, neurological, gastrointestinal, musculoskeletal, and psychiatric diseases from which the students believe they suffer. Symptom expectations for the various ailments are learned in the classroom. Selective attention to and reattribution of symptoms that frequently occur in the normal population results. Anxiety about the illness, the situational stress of medical school, and an erosion of belief in personal invulnerability produced by treating patients enhance illness perceptions. Medical students' disease resolves following reassurance, confirmation of the absence of illness by examination, and anxiety reduction. ${ }^{27}$ Like medical students' disease, PCS symptoms occur frequently in the normal population and in the context of anxiety arousing circumstances that challenge beliefs of personal invulnerability. The aetiology of both syndromes may also involve symptom expectations.

Expectations become salient when the patient lacks an obvious, immediate, and adequate alternative explanation for their symptoms. ${ }^{1719}$ The incidence of PCS is higher when patients receive no explanation of their symptoms and are not provided treatment or encouragement. ${ }^{28}$ Supportive intervention consisting of education and reassurance of a favourable prognosis has been recommended. $^{2129}$ Supportive treatment appears to be effective, ${ }^{30}$ although adequate outcome studies are lacking. The current aetiological model also suggests that relaxation training and cognitivebehavioural therapies may be effective treatments for anxiety and depression in at least some PCS patients. However, studies addressing this issue are not available. Given the high rates at which PCS occurs and persists, and its resistance to current interventions, empirical treatment outcome studies appear to be necessary.

The extent to which these conclusions can be generalised may be limited by several methodological considerations. The head trauma group was drawn from consecutive outpatient referrals for neuropsychological examination rather than from consecutive hospital admissions for mild head injury. Current results may therefore characterise the responses of patients with prominent postconcussion complaints better than those of individuals with head injuries in general. Patients with head trauma were seen an average of 1.7 years after injury. The results may provide better clarification of the presentation of patients with persistent postconcussion syndrome. Many of the symptoms following mild head injury would have already resolved by this time, and this may have reduced the frequency of reported symptoms. Conversely, the use of a checklist of symptoms may have increased the frequency of reporting symptoms. Although this influence may affect the reports of both groups, the correspondence betwen the expectation and the experience of postconcussion syndrome would not be altered.

This paper was presented in part at the 97th annual convention of the American Psychological Association, New Orleans, Louisiana, USA, 1989. 
1 World Health Organization. Mental disorders: glossary and guide to their classification in accordance with the 9th revision of the international classification of diseases. Geneva: WHO, 1978.

2 Alves WM, Colohan AR, O'Leary TJ, Rimel RW, Jane JA. Understanding post-traumatic symptoms after minor head injury. 7 Head Trauma Rehab 1986;1:1-12.

3 Merskey H, Woodforde JM. Psychiatric sequelae of minor head injury. Brain 1972;95:521-8.

4 Rutherford WH. Postconcussion symptoms: Relationship to acute neurological indices, individual differences, and circumstances of injury. In: Levin, HS, Eisbenbers HM, circumstances of injury. In: Levin, HS, Eisbenberg HM, Benton AL, eds. M

5 McMordie WR. Twenty-year follow-up of the prevailing opinion on the posttraumatic or postconcussional syndrome. Clinical Neuropsychologist 1988;2:198-212.

6 Binder LM. Persisting symptoms after mild head injury: A review of the postconcussive syndrome. $\mathcal{F}$ Clin Exper Neuropsychol 1986;8:323-46.

7 Levin HS, Benton AL, Grossman RG. Neurobehavioral consegue 1982

8 Lidvall $\mathrm{HF}$, Linderoth B, Norlin B. Causes of the postconcussional syndrome. Acta Neurol Scand 1974;50: (Suppl. 56).

9 Miller H Accident neurosis. BMF 1961;1:919-25.

10 Rutherford WH, Merrett JD, McDonald JR. Symptoms at one year following concussion from minor head injuries. Injury 1979;10:225-30.

11 Levin HS, Mattis S, Ruff RM, Eisenberg HM, Marshall LF, Tabaddor $\mathrm{K}$, et al. Neurobehavioral outcome following minor head injury: A three-center study. $\mathcal{f}$ Neurosurg 1987;66:234-43.

12 McLean A, Temkin NR, Dikmen S, Wyler AR. The behavioral sequelae of head injury. $\mathcal{f}$ Clin Neuropsychol 1983;5:361-76.

13 McLean A, Dikmen S, Temkin N, Wyler AR, Gale JL. Psychosocial functioning at one month after head injury. Neurosurg 1984;14:393-9.

14 Rutherford WH, Merrett JD, McDonald JR. Sequelae of concussion caused by minor head injuries. Lancet 1977;1:1-4.

15 Shoenhuber $R$, Gentilini $M$. Neurophysiological assessment of mild head injury. In: Levin HS, Eisenberg HM, Benton AL, eds. Mild head injury. New York: Oxford Press, 1989:142-52.
16 Gouvier WD, Uddo-Crane M, Brown LM. Base rates of post-concussional symptoms. Arch Clin Neuropsychol 1988;3:273-8.

17 Barsky AJ, Klerman GL. Overview: Hypochondriasis, bodily complaints, and somatic styles bodily complaints, and somatic styles. Am F Psychiatry 1983;140:273-83.

18 Reisenzein $R$. The Schachter theory of emotion: Two decades later. Psycholog Bull 1983;94:239-64.

19 Schachter S, Singer JE. Cognitive, social, and physiological determinants of emotional state. Psycholog Rev 1962;69:379-99.

20 Barona A, Reynolds CR, Chastain R. A demographically based index of premorbid intelligence for the WAIS-R. $\mathcal{f}$ Consult Clin Psychol 1984;52:885-7.

21 Levin HS, Eisenberg HM, Benton AL. Mild head injury, New York: Oxford Press, 1989.

22 Black $P$, Jeffries J, Blumer $D$, Wellner $A$, Walker AE. Th post-traumatic syndrome in children. In: Walker $A E$ Caveness WF, Critchley M, eds. The late effects of head injury. Springfield, Illinois: Charles C Thomas, 1969:142-9.

23 Casey R, Ludwig S, McCormick MS. Morbidity following minor head trauma in children. Pediatrics 1986;78:497-502

24 Barth JT, Alves WM, Ryan TV, et al. Mild head injury in sports: Neuropsychological sequelae and recovery of function. In: Levin HS, Eisenberg HM, Benton AL, eds. Mild head injury, New York: Oxford Press, 1989:142-52.

25 Cook JB. The effects of minor head injuries sustained in sport and the postconcussional syndrome. In: Walker AE Caveness WF, Critchley M, eds. The late effects of head injury. Springfield, Illinois: Charles C. Thomas, 1969:408-13.

26 Kellner R. Functional somatic symptoms and hypochondriasis. Arch Gen Psychiatry 1985;42:821-33.

27 Mechanic D. Social psychologic factors affecting the presentation of bodily complaints. $N$ Engl $f$ Med 1972;286:1132-9.

28 Kelly RE. The post-traumatic syndrome. Pahlavi Medical fournal 1972;3:530-47.

29 Long CJ, NovackTA. Post-concussion symptoms after head trauma: Interpretation and treatment. Southern Medical trauma: Interpretation and

30 Kelly RE. The post-traumatic syndrome: An iatrogenic disease. Forensic Science 1975;6:17-24. 